\title{
Lipomas mesentéricos múltiplos em equino jovem: relato de caso
}

Gustavo dos Santos Rosa, Juliana de Moura Alonso, Marilia Ferrari Marsiglia, Mariana Lopes da Conceiçao, Tatiane Velalva de Paula, Carlos Alberto Hussni, Ana Liz Garcia Alves, Celso Antônio Rodrigues, Marcos Jun Watanabe*

Faculdade de Medicina Veterinária e Zootecnia, Universidade Estadual Paulista (UNESP), Botucatu, SP, Brasil

*Autor correspondente

e-mail: watanabe@fmvz.unesp.br

\section{Resumo}

Embora a maioria dos lipomas mesentéricos ocorra sem consequências clínicas, a obstrução estrangulante (OE) por lipomas pedunculados é responsável por até $10 \%$ de todas as cirurgias abdominais em equinos e até $30 \%$ de todas as OE de intestino delgado (ID). 0 presente trabalho relata um caso atípico de OE por lipoma em um equino jovem, demonstrando os achados ultrassonográficos e discutindo a abordagem cirúrgica e seu prognóstico, baseado em um protocolo de avaliação de viabilidade intestinal. 0 protocolo consiste na avaliação macroscópica do intestino 15 minutos após reversão do estrangulamento, com classificação em cinco graus. Lesões de grau I sugerem menor acometimento, sem necessidade de enterectomia. Já lesões de grau IV e V possuem caráter irreversível, requerendo a excisão do segmento acometido. A graduação é inferida de acordo com a cor da serosa, espessura da parede, presença de lesões hemorrágicas e de motilidade espontânea ou induzida mecanicamente através de pressão digital. Um equino macho de 9 anos de idade foi atendido no HV-UNESP Botucatu com desconforto abdominal agudo, taquicardia e atonia intestinal total. Através da palpação transretal foi possível identificar alças de ID distendidas e uma massa firme e arredondada na região abdominal caudodorsal direita. Realizou-se a ultrassonografia, que confirmou a presença da referida massa, apresentando aproximadamente $10 \mathrm{~cm}$ de diâmetro e padrão heterogêneo. A massa encontrava-se cercada por segmentos de ID distendidos por líquido e atônicos. A paracentese revelou grande quantidade de líquido com coloração avermelhada e turva. Devido aos achados do exame físico, ultrassonográfico e laboratoriais, o animal foi submetido à celiotomia. Durante a exploração abdominal, observou-se aproximadamente $80 \%$ do íleo com coloração roxa, parede espessada e distensão por líquido. Três massas foram encontradas, medindo 18 x 13,5 cm, 9,5 x 8,5 cm e 6 x 7 cm e 1288 g, 413 g e 96 g, respectivamente. Duas delas - a maior e a menor - possuíam o aspecto típico de lipomas, com consistência mole, cor amarela e aspecto gorduroso. A massa menor estava aderida ao 
mesentério; a maior encontrava-se aderida à serosa ileal, causando obstrução intestinal extraluminal. A terceira massa possuía consistência firme, coloração rósea e aspecto fibroso e bastante reativo, parcialmente envolta pelo omento. Seu pedículo causava estrangulamento à porção jejunal aboral. Após a excisão das três massas, o intestino retomou a motilidade e a coloração rósea, classificando-o como grau II segundo o protocolo descrito. Deste modo, optou-se pela não realização de enterectomia. 0 paciente desenvolveu ileus pós-operatório refratário à terapia pró-cinética. Nova avaliação ultrassonográfica foi realizada, sendo possível visualizar espessamento da parede do ID, com atonia e distensão. Após 48 horas de cuidados intensivos sem resposta, o paciente apresentou dor severa sem resposta à medicação analgésica. Devido à ausência de alternativas terapêuticas restantes, optou-se pela eutanásia. A necropsia revelou necrose severa do íleo, além de petéquias e equimoses na serosa jejunal aboral. Adicionalmente, outros três lipomas assintomáticos com $4 \mathrm{~cm}$ de diâmetro foram encontrados aderidos ao mesentério e mesocólon. 0 presente caso demonstra que embora a idade média para a ocorrência de lipomas esteja entre 17 e 19 anos, estes podem ocorrer em animais jovens. A ultrassonografia abdominal foi uma importante ferramenta para a detecção dos lipomas e acompanhamento da condição intestinal pós-operatória. 0 aspecto ileal justificou a conduta tomada, segundo protocolo publicado anteriormente. Contudo, a necropsia demonstrou lesões intestinais irreversíveis, não corroborando com o referido protocolo. Em conclusão, OEs devido a lipomas devem ser consideradas como diagnóstico diferencial em cólicas com sede provável no ID. A associação de técnicas diagnósticas pode colaborar com a detecção e intervenção precoces, aumentando o sucesso sem a realização de enterectomia.

Palavras-chave: Enterectomia. Lipoma pedunculado. Ileus. 